\title{
Risky sexual behavior among Iranian university students and its relationship with religiosity and familial support
}

\author{
SIMA AFRASHTEH ${ }^{1, A-F}$, ABBAS ABBASI-GHAHRAMANLOO², A, c, MOHEBAT VALI 1, D, E, \\ ORCID ID: 0000-0002-4276-2084
ORCID ID: 0000-0001-7733-2116 \\ HALEH GHAEM ${ }^{3, \text { A, D }}$, ABOLFAZL MOHAMMADBEIGI 4, D, F, HAMID TABATABAEE ${ }^{3, \text { A }}$, \\ SADEGH KARGARIAN-MARVASTI $5, \mathrm{~B}, \mathrm{D}, \mathrm{F}$
}

\author{
${ }^{1}$ Student Research Committee, Shiraz University of Medical Sciences, Shiraz, Iran \\ ${ }^{2}$ Department of Epidemiology, Faculty of Health, Iran University of Medical Sciences, Tehran, Iran \\ ${ }^{3}$ Research Center for Health Sciences, Institute of Health, Department of Epidemiology, School of Health, Shiraz \\ University of Medical Sciences, Shiraz, Iran \\ ${ }^{4}$ Research Center for Environmental Pollutants, Department of Epidemiology and Biostatistics, Qom University \\ of Medical Sciences, Qom, Iran \\ ${ }^{5}$ Isfahan University of Medical Sciences, Isfahan, Iran
}

A - Study Design, B - Data Collection, C - Statistical Analysis, D - Data Interpretation, E - Manuscript Preparation, F - Literature Search, $\mathbf{G}$ - Funds Collection

\begin{abstract}
Summary Background. Risky sexual behavior (RSB) has emerged as an important public health issue worldwide. Objectives. This study was aimed at evaluating the prevalence of RSB and its risk factors regarding family support and religious beliefs, as well as other risky behaviors among college students in Bushehr city.

Material and methods. This cross-sectional study was conducted on a total of 977 students of Bushehr city, southern Iran, in 2016. Participants were selected using multistage sampling. Data collection was performed using a self-administered questionnaire comprised of data on extramarital sexual behavior at three different time points. Data was analyzed using SPSS version 16.0 with the chi-squire test, independent samples $t$-test and logistic regression.

Results. The overall prevalence of RSB was $5.6 \%$, and the lifetime, past year and past month prevalence of extramarital sexual activity was $9.9 \%, 8.1 \%$ and $4.7 \%$, respectively. Approx. $1.5 \%$ of the students also reported alcohol and other drug use at last sex and $3.7 \%$ reported having sexual intercourse without a condom. The results revealed that age $(O R=1.10)$, male gender $(O R=2.85)$, smoking $(O R$ $=2.27)$, hookah use $(O R=2.23)$, alcohol use $(O R=6.08)$ and family support $(O R=0.97)$ were significantly associated with extramarital sex. Moreover, male gender $(O R=1.94)$, age $(O R=1.10)$, hookah use $(O R=2.94)$, illicit drug use $(O R=3.80)$ and religiosity $(O R=0.98)$ were associated with RSB.

Conclusions. There is a concurrence of high-risk sexual behaviors in Iranian students and the experience of high-risk behavior is related to other RSBs. Therefore, effective training interventions and programs should be designed and implemented to reduce risky behaviors, especially sexual behaviors.

Key words: risk, sexual behavior, religion, students.
\end{abstract}

Afrashteh S, Abbasi-Ghahramanloo A, Vali M, Ghaem H, Mohammadbeigi A, Tabatabaee H, Kargarian-Marvasti S. Risky sexual behavior among Iranian university students and its relationship with religiosity and familial support. Fam Med Prim Care Rev 2020; 22(4): 319-324, doi: https://doi.org/10.5114/fmpcr.2020.100428.

\section{Background}

Sexual behavior as a global public health issue among youth aged 15-24 years is categorized into three types, including unprotected vaginal, oral and anal intercourse [1]. Risky sexual behavior (RSB) is the main cause of an increased number of sexually transmitted infections (STIS) amongst young people, and one-third of nearly 340 million cases of STIs occurred among young people under the age of $25[2,3]$.

University students are young people that are exposed to a variety of RSBs, including early sexual initiation, multiple sexual partners, unprotected sex, homosexual sex and alcohol and drug use during sexual activity [1]. The results of other studies in various countries showed a high prevalence of RSB among college students. For example, the prevalence of RSB was reported as being $50.9 \%$ in American students, $26.4 \%$ in Russian students and $33.8 \%$ among Turkish students [4-6]. In addition, an upward prevalence of RSB has been shown in developing countries [7, 8]. Studies conducted in India and China showed the prevalence of RSB as being $17.6 \%$ and $21 \%$, respectively $[9,10]$.

Iran is a religious country, and most are Muslims. Therefore, similar to other religious countries, premarital sex is sinful and prohibited. It is believed that the increased age of marriage in both men and women significantly increases RSB among youth, particularly students living far away from home in Iran [11]. However, recent reports in Iran showed that the incidence of HIV/AIDS cases in People Who Inject Drugs (PWID), Female Sex Workers (FSW) and prisoners is decreasing [12], but in recent years, morbidity has increased in young people due to unsafe sex, and the estimated number of HIV-infected people is more than 110,000 [13]. However, the prevalence of RSB in young people in Iran is varied among studies. Safiri et al. reported the prevalence of RSB as being 5.5\% amongst Iranian students [14]. Another study also reported the prevalence of extramarital sex as being $10.8 \%$ [15]. 
Previous studies have shown that factors such as smoking and drug use, low- and high-income families, domestic violence against women, alcohol use, delinquent peers, poor self-control and history of psychiatric disorders, including sexual assault and suicide, were positively associated with RSB [16-20]. Furthermore, improved religious beliefs and behaviors and strong family support were associated with reduced RSB among students $[15,21]$. Due to the controversy among RSB, family support and religiosity and the limited number of studies that examined the relationship between RSB and religiosity and family support in Iran, this study was aimed at evaluating the prevalence of RSB and its relation with other risky behaviors, family support and religiosity among Iranian college students.

\section{Material and methods}

\section{Study design and participants}

This cross-sectional study was conducted on a total of 977 students in Bushehr city, southern Iran, in 2016. Participants were selected using multistage sampling. First, all students of the target university were listed. Classes (clusters) were then randomly selected from each college, and all students of each selected class were recruited into the study. The exclusion criteria include people under the age of 18 or people who did not agree to participate in the study.

\section{Measures}

Data collection was performed using a standard self-administered questionnaire. Accordingly, extramarital sex was measured at three different points in time: lifetime, over the past year and over the past month. As such, the question was "Did you have any sex (vaginal, oral or anal) with a partner of the opposite sex in your lifetime/over the past year/over the past month?" The Young Risky Sexual Behavior (YRSB) questionnaire is a standard tool in the Iranian community that was used in a previous study and was applied to collect the required data [15]. This questionnaire evaluated RSB in three domains, including drug or alcohol use during the last sexual intercourse, sex with more than one partner and lack of condom use in the last sexual intercourse. The content validity of this tool was approved by an epidemiologist, psychologist and sociologist. All participants were informed about the purpose of the study to insure confidentiality. All subjects also entered the study voluntarily. Data on demographic characteristics, smoking, hookah use, alcohol use, illicit drug use and physical conflict was obtained to investigate the relation between sexual behaviors and these variables. The 13-item Aneshensel \& Sucoff parental support scale was also used to assess family support among students. Moreover, the religious beliefs of the participants were evaluated using Kendler's general religiosity scale. More details about the questionnaire used in the current study are reported on in our recent article (ref). The parental support scale and Kendler's general religiosity scale were valid and reliable tools that were used in Iranian studies, and their validity was approved $[15,22]$.

\section{Statistical analyses}

Data was analyzed using SPSS version 16.0 with the chi-squire test and independent samples $t$-test. The logistic regression (backward model) was also used to assess multiple relations between RSB and extramarital sex in the last year with other related factors.

\section{Ethical considerations}

All procedures performed in this study on human participants were in accordance with the ethical standards of the insti- tution and the national research committee, as well as with the 1964 Helsinki declaration and its later amendments and comparable ethical standards. Participation in the study was voluntary. After getting acquainted with the research project, each participant expressed their written consent to participate in the study. The study was approved by the Ethics Committee of the Shiraz University of Medical Sciences (no. IR.Sums.REC.1395.S1246).

\section{Results}

A total of 977 students entered this study, with the mean age of the participants being $21.11 \pm 2.32$ years (ranging from 17 to 39 years), and $58 \%$ were female. The mean of religious beliefs and family support was $112.57 \pm 20.49$ and $50.57 \pm 10.34$, respectively. The prevalence of RSB and extramarital sex is presented in Table 1. The overall prevalence of RSB was calculated as being $5.6 \%$ among students. Approx. $1.5 \%$ of the participants reported alcohol and other drug use during the last sexual intercourse, and 3.7\% reported having sexual intercourse without a condom, and $1.6 \%$ reported multiple sex partners. Accordingly, the lifetime, past year and past month prevalence of extramarital sex was $9.9 \%, 8.1 \%$ and $4.7 \%$, respectively. Approx. $0.7 \%$ of the participants reported daily or almost daily extramarital sex with a partner of the opposite sex. The lifetime, past year and past month prevalence of extramarital sex was shown to be higher in men than in women.

\begin{tabular}{|c|c|c|c|c|c|c|}
\hline \multirow[b]{2}{*}{ Items } & \multicolumn{2}{|c|}{ Male } & \multicolumn{2}{|c|}{ Female } & \multicolumn{2}{|c|}{ Total } \\
\hline & $n$ & $\%$ & $n$ & $\%$ & $n$ & $\%$ \\
\hline \multicolumn{7}{|l|}{ Extra marital sex } \\
\hline $\begin{array}{l}\text { Lifetime extramarital } \\
\text { sex }\end{array}$ & 71 & 17.6 & 26 & 4.5 & 97 & 9.9 \\
\hline $\begin{array}{l}\text { Last year extramarital } \\
\text { sex }\end{array}$ & 59 & 14.6 & 20 & 3.5 & 79 & 8.1 \\
\hline $\begin{array}{l}\text { Last month extra- } \\
\text { marital sex }\end{array}$ & 34 & 8.4 & 12 & 2.1 & 46 & 4.7 \\
\hline $\begin{array}{l}\text { Daily or almost daily } \\
\text { in past month }\end{array}$ & 5 & 1.2 & 2 & 0.3 & 7 & 0.7 \\
\hline $\begin{array}{l}\text { High-risk sexual } \\
\text { behavior* }\end{array}$ & 37 & 9.2 & 18 & 3.1 & 55 & 5.6 \\
\hline $\begin{array}{l}\text { Using drugs or alco- } \\
\text { hol before the last } \\
\text { sexual relationship }\end{array}$ & 10 & 2.5 & 5 & 0.9 & 15 & 1.5 \\
\hline $\begin{array}{l}\text { Sexual intercourse } \\
\text { with numerous } \\
\text { persons }\end{array}$ & 13 & 3.2 & 3 & 0.5 & 16 & 1.6 \\
\hline $\begin{array}{l}\text { Sexual intercourse } \\
\text { without using a con- } \\
\text { dom }\end{array}$ & 22 & 5.4 & 14 & 2.4 & 36 & 3.7 \\
\hline
\end{tabular}

* Includes using drugs or alcohol before the last sexual relationship or sexual intercourse with numerous persons or sexual intercourse without using a condom.

Demographic characteristics and factors associated with extramarital sex and RSB are shown in Table 2. The results show that male gender, age, hookah use, smoking, illicit drug use (OR $=3.80$ ) and alcohol use were significantly associated with RSB and extramarital sex $(p<0.05)$. The variable 'living with parents' was significantly associated with extramarital sex $(p<0.05)$. The mean scores of family support and religiosity were significantly lower in students with a history of extramarital sex and RSB.

The results of logistic regression analysis are presented in Table 3. After adjusting for other variables, there was a significant relationship between age $(O R=1.10)$, male gender $(O R=$ 


\begin{tabular}{|c|c|c|c|c|c|c|c|}
\hline \multirow[t]{3}{*}{ Characteristics } & \multicolumn{2}{|c|}{ Extramarital sex (last year) } & \multirow[t]{3}{*}{$p$} & \multicolumn{2}{|c|}{ High-risk sexual behavior } & \multirow[t]{3}{*}{$p$} & \multirow[t]{3}{*}{$n$} \\
\hline & no & yes & & no & yes & & \\
\hline & $n(\%)$ & $n(\%)$ & & $n(\%)$ & $n(\%)$ & & \\
\hline $\begin{array}{l}\text { Gender } \\
\text { male } \\
\text { female }\end{array}$ & $\begin{array}{l}345(85.4) \\
553(96.5) \\
\end{array}$ & $\begin{array}{l}59(14.6) \\
20(3.5) \\
\end{array}$ & $<0.001$ & $\begin{array}{l}367(90.8) \\
555(96.9) \\
\end{array}$ & $\begin{array}{l}37(9.2) \\
18(3.1)\end{array}$ & $<0.001$ & $\begin{array}{l}404 \\
573\end{array}$ \\
\hline $\begin{array}{l}\text { Marital status } \\
\text { single } \\
\text { married } \\
\end{array}$ & $\begin{array}{l}781(92.0) \\
117(91.4) \\
\end{array}$ & $\begin{array}{l}68(8.0) \\
11(8.6) \\
\end{array}$ & 0.821 & $\begin{array}{l}804(94.7) \\
118(92.2) \\
\end{array}$ & $\begin{array}{l}45(5.3) \\
10(7.8) \\
\end{array}$ & 0.250 & $\begin{array}{l}849 \\
128\end{array}$ \\
\hline $\begin{array}{l}\text { Living in } \\
\text { parental home } \\
\text { dormitory } \\
\text { single house } \\
\end{array}$ & $\begin{array}{l}207(88.8) \\
624(93.8) \\
67(84.8) \\
\end{array}$ & $\begin{array}{l}26(11.2) \\
41(6.2) \\
12(15.2) \\
\end{array}$ & 0.003 & $\begin{array}{l}220(94.4) \\
629(94.6) \\
73(92.4) \\
\end{array}$ & $\begin{array}{l}13(5.6) \\
36(5.4) \\
6(7.6)\end{array}$ & 0.728 & $\begin{array}{l}233 \\
665 \\
79 \\
\end{array}$ \\
\hline $\begin{array}{l}\text { Residency status } \\
\text { native } \\
\text { non-aboriginal }\end{array}$ & $\begin{array}{l}472(91.7) \\
426(92.2)\end{array}$ & $\begin{array}{l}43(8.3) \\
36(7.8)\end{array}$ & 0.750 & $\begin{array}{l}488(94.8) \\
434(93.9)\end{array}$ & $\begin{array}{l}27(5.2) \\
28(6.1)\end{array}$ & 0.580 & $\begin{array}{l}515 \\
462\end{array}$ \\
\hline $\begin{array}{l}\text { Working along with } \\
\text { education } \\
\text { yes } \\
\text { no }\end{array}$ & $\begin{array}{l}122(84.1) \\
776(93.3)\end{array}$ & $\begin{array}{l}23(15.9) \\
56(6.7)\end{array}$ & $<0.001$ & $\begin{array}{l}127(87.6) \\
795(95.6) \\
\end{array}$ & $\begin{array}{l}18(12.4) \\
37(4.4)\end{array}$ & $<0.001$ & $\begin{array}{l}145 \\
832\end{array}$ \\
\hline $\begin{array}{l}\text { Cigarette smoking (last } \\
\text { month) } \\
\text { yes } \\
\text { no }\end{array}$ & $\begin{array}{l}65(66.3) \\
833(94.8)\end{array}$ & $\begin{array}{l}33(33.7) \\
46(5.2)\end{array}$ & $<0.001$ & $\begin{array}{l}80(81.6) \\
842(95.8)\end{array}$ & $\begin{array}{l}18(18.4) \\
37(4.2)\end{array}$ & $<0.001$ & $\begin{array}{l}68 \\
909\end{array}$ \\
\hline $\begin{array}{l}\text { Hookah use (last month) } \\
\text { yes } \\
\text { no }\end{array}$ & \begin{tabular}{|l}
$117(74.5)$ \\
$781(95.2)$ \\
\end{tabular} & $\begin{array}{l}40(25.5) \\
39(4.8)\end{array}$ & $<0.001$ & $\begin{array}{l}133(84.7) \\
789(96.2) \\
\end{array}$ & $\begin{array}{l}24(15.3) \\
31(3.8)\end{array}$ & $<0.001$ & $\begin{array}{l}94 \\
883 \\
\end{array}$ \\
\hline $\begin{array}{l}\text { Alcohol use (last month) } \\
\text { yes } \\
\text { no }\end{array}$ & \begin{tabular}{|l|}
$27(48.6)$ \\
$871(94.8)$ \\
\end{tabular} & $\begin{array}{l}31(53.4) \\
48(5.2)\end{array}$ & $<0.001$ & $\begin{array}{l}42(72.4) \\
880(95.8)\end{array}$ & $\begin{array}{l}16(27.6) \\
39(4.2)\end{array}$ & $<0.001$ & $\begin{array}{l}39 \\
938\end{array}$ \\
\hline $\begin{array}{l}\text { Illicit drug use (lifetime) } \\
\text { yes } \\
\text { no }\end{array}$ & \begin{tabular}{|l|}
$26(66.7)$ \\
$872(93.0)$ \\
\end{tabular} & $\begin{array}{l}13(33.3) \\
66(7.0)\end{array}$ & $<0.001$ & $\begin{array}{l}28(71.8) \\
894(95.3)\end{array}$ & $\begin{array}{l}11(28.2) \\
44(4.7)\end{array}$ & $<0.001$ & $\begin{array}{l}39 \\
938\end{array}$ \\
\hline $\begin{array}{l}\text { Physical fight (last year) } \\
\text { yes } \\
\text { no }\end{array}$ & $\begin{array}{l}55(79.7) \\
843(92.8)\end{array}$ & $\begin{array}{l}14(20.3) \\
65(7.2)\end{array}$ & $<0.001$ & $\begin{array}{l}57(82.6) \\
865(95.3)\end{array}$ & $\begin{array}{l}12(17.4) \\
43(4.7)\end{array}$ & $<0.001$ & $\begin{array}{l}69 \\
908\end{array}$ \\
\hline Age (mean \pm SD) & $21.05 \pm 2.17$ & $21.86 \pm 3.52$ & 0.048 & $21.07 \pm 2.19$ & $21.87 \pm 3.80$ & 0.128 & $21.12 \pm 2.32$ \\
\hline $\begin{array}{l}\text { Score of religious beliefs } \\
\text { (mean } \pm \text { SD) }\end{array}$ & $113.98 \pm 19.15$ & $96.70 \pm 27.52$ & $<0.001$ & $113.41 \pm 19.76$ & $98.67 \pm 26.88$ & $<0.001$ & $112.58 \pm 20.50$ \\
\hline $\begin{array}{l}\text { Score of familial support } \\
\text { (mean } \pm \text { SD) }\end{array}$ & $51.05 \pm 10.04$ & $45.08 \pm 12.04$ & $<0.001$ & $50.91 \pm 10.09$ & $44.80 \pm 12.64$ & 0.001 & $50.57 \pm 10.34$ \\
\hline
\end{tabular}

\begin{tabular}{|c|c|c|c|c|c|c|}
\hline \multirow[t]{2}{*}{ Variables } & \multicolumn{3}{|c|}{ Extramarital sex (last year) } & \multicolumn{3}{|c|}{ High-risk sexual behavior } \\
\hline & OR & $95 \% \mathrm{Cl}$ & $p$ & OR & $95 \% \mathrm{Cl}$ & $p$ \\
\hline Age & 1.10 & $1.01-1.20$ & 0.028 & 1.10 & $1.01-1.21$ & 0.036 \\
\hline Gender (male) & 2.85 & $1.60-5.07$ & $<0.001$ & 1.94 & $1.04-3.61$ & 0.037 \\
\hline Cigarette smoking (last month) & 2.27 & $1.13-4.58$ & 0.021 & - & - & - \\
\hline Hookah use (last month) & 2.33 & $1.21-4.45$ & 0.011 & 2.94 & $1.59-5.45$ & 0.001 \\
\hline Alcohol use (last month) & 6.08 & 2.99-12.39 & $<0.001$ & - & - & - \\
\hline Score of familial support & 0.97 & $0.95-0.99$ & 0.028 & - & - & - \\
\hline Illicit drug use (lifetime) & - & - & - & 3.80 & $1.64-8.79$ & 0.002 \\
\hline Score of religious beliefs & - & - & - & 0.98 & $0.97-0.99$ & 0.001 \\
\hline
\end{tabular}

$2.85)$, smoking $(O R=2.27)$, hookah use $(O R=2.23)$, alcohol use $(O R=6.08)$ and family support $(O R=0.97)$ with extramarital sex. In addition, male gender $(O R=1.94)$, age $(O R=1.10)$, hookah use $(O R=2.94)$, illicit drug use $(O R=3.80)$ and religiosity $(O R=$ $0.98)$ were associated with RSB. Goodness-of-fit for the regression model was checked by the Akaike Information Criteria (AIC) and Hosmer-Lemeshow test. The highest steps of model have the best fitness.

\section{Discussion}

According to the findings of this study, the lifetime, past year and past month prevalence of extramarital sexual activity was 
$9.9 \%, 8.9 \%$ and $4.7 \%$, respectively. The results of many studies conducted in Western and Asian countries revealed that extramarital sex is more prevalent among youth [23-26]. However, the prevalence of extramarital sex was reported as lower in Iran compared with other countries, which was in accordance with the results of our study [27]. In Iran, sexual intercourse out of marriage is prohibited and is religiously unacceptable and sinful, and this could be a reason for non-reporting by the participants in the study. We attempted to reduce this limitation by building trust and creating a private space for the participants and by using an anonymous questionnaire.

The findings of this study also revealed that the overall prevalence of RSB is lower in this study compared with previous studies. For instance, Derbie et al. reported the prevalence of RSB as being $28.4 \%$ [1]. Another study indicated the prevalence of RSB as being more than $69 \%$ [28]. Two studies conducted in Iran reported the prevalence of RSB as being $5.6 \%$ and $10.7 \%$ $[29,30]$. These differences may be due to cultural differences in various societies. Moreover, due to the use of a self-administered questionnaire in the present study, the measured prevalence of RSB is less than the expected value. It should also be noted that differences in the prevalence of RSB may be due to the different implications of RSB used in various studies.

According to our study, having sex without the use of a condom and having multiple sex partners is lower than in other studies. A study in China revealed that $24.8 \%$ of students used a condom during sexual intercourse, and $3.6 \%$ reported having multiple sex partners [31]. A study conducted in Shiraz city also revealed that $23.8 \%$ of the students had premarital sex without the use of a condom [32]. These differences can also be due to religious differences, as well as differences in the level of family support for young people in different countries and regions. Usually, in Iran, especially in more religious areas, family support for young people is higher, and this difference in Bushehr, which is a more traditional city than Shiraz, may be the reason.

Lack of use of a condom during sexual intercourse can significantly increase the risk of sexually transmitted diseases, such as AIDS, hepatitis, sexually transmitted infections and genital warts, as well as unintended pregnancies and cervical cancer in women.

In Iran, religious laws and costums regarding sexual activity out of marriage make those involved in these activities do this secretly due to fear, social stigma, etc. Moreover, as there are usually no adequate education courses regarding sexuality and sexual behavior in schools and universities, these students are more likely to be involved in RSB. As such, these individuals may not have access to a condom. Although, in this study, few students reported RSB, it is strongly suggested to place this subject in the curriculum at Iranian universities to improve students' knowledge towards RSB.

A number of previous studies suggest that religiosity and family support can have a protective effect in preventing RSB $[22,30]$. In the present study, after adjusting for confounding effects, higher scores of family support reduced the risk of extramarital sex. It is also important to note that poor friendship between parents and children, humiliation, banning and reprimanding, criticism, loneliness and neglect may force children to make friends with the opposite sex and possibly experience safe or unsafe sexual intercourse [33]. It seems that lack of emotional support from parents encourages children to establish relationships with the opposite sex to compensate for emotional deficiency, and thus the individual may do anything, including sexual intercourse, to maintain the friendship of the opposite sex. In this regard, parents must first be aware of the potential risks of having sex outside of marriage. Furthermore, family support, especially at an academic age, may reduce the likelihood of committing these risky sexual behaviors.

The effective role of religious beliefs in preventing RSB has always been focused on by Iranian and other researchers all around the world $[22,30]$. The results of the present paper show that higher scores of religious beliefs reduced the risk of RSB. Abebe et al. stated that students who spend more time in religious places are less likely to display RSB [34]. Another study showed that religious people mostly seek out conditions in which their sexual behavior is acceptable, and subsequently, the likelihood of having multiple sex partners is lower among these individuals [35]. According to this evidence, religious people have better mental and behavioral health than the non-religious people. Religious orders for safe behaviors, alcohol and drug abuse which are believed to cause harm to oneself and others, and condemning risky sexual behavior in different religions makes religious people less likely to be exposed to RSB. Therefore, it is necessary for university courses to emphasize the promotion of the religious beliefs of students.

The results of logistic regression analysis revealed that older age and male gender were positively associated with extramarital sex and RSB. Previous studies showed that older age is significantly associated with RSB $[31,36]$. With age, the sense of autonomy increases in individuals, and men are more likely to engage in RSB due to greater autonomy, lower parental monitoring and the risk-taking behaviors among these individuals. Alcohol use is another risk factor for RSB among youth. Accordingly, Choudhry et al. reported that alcohol consumption was significantly associated with having multiple sex partners [37]. There is also evidence that alcohol consumption is associated with the onset of RSB [36]. The findings of the present study were consistent with the results of previous studies on the relation between alcohol consumption and RSB.

The results of this study indicate the co-occurrence of sexual behavior out of marriage, as well as RSB with other high-risk behaviors. For example, hookah use and the illicit drug use were associated with RSB. Much attention has been paid to the co-occurrence of RSB in a large number of studies [30, 38, 39]. Therefore, all high-risk behaviors should be considered in RSB prevention programs to effectively reduce risky behaviors, especially sexual behaviors.

Although our results showed the pattern of RBS in the college students of southern Iran, most young people were in this area for the first time. Nevertheless, some limitations might be seen our results. First, like any other cross-sectional study, it is affected by an inherent bias, as exposure and outcome are measured at the same time. Therefore, this relationship does not necessarily have a cause-and-effect relationship, and in these circumstances, it is impossible to establish a temporal relationship between exposure and the onset of the outcome. Some students were also barred from participating in the study, which could expose our results to selection bias. Due to religious concerns and the social desirability effect, our estimates are underestimated. Furthermore, multicenter studies with different religious and ethnicities could yield more accurate estimates. However, despite these limitations, our study includes a large representative sample of Bushehr students. Therefore, the body of evidence can be a good view of the prevalence of RBS and related factors among Iranian students. Since this study was performed on students of Bushehr University, it cannot be said that the results show the general population. Therefore, we suggest that in the future, studies in different countries and with different ethnicities and cultures, especially in Islamic countries, should be addressed to RBS according to the views of the families in these countries, as well as studies at lower ages, including high school students, in order to reduce the age of occurrence of high-risk behaviors in recent years.

\section{Conclusions}

The findings of the present paper showed the prevalence of sexual practices and RSB in university students in southern Iran for the first time and showed the effect of other risky behaviors on external sexual activities. However, due to religious con- 
cerns and the social desirability effect, such as fear and social stigma, our results are underestimated. Based on our results, there was a co-occurrence of risky sexual behaviors and other risk-taking behaviors. Nevertheless, family support and religion were shown as protective factors for RSB. Therefore, effective training interventions should be designed and implemented to empower individuals and improve life skills to reduce risky behaviors, especially sexual behaviors.

Abbreviations. RSB - Risky Sexual Bbehavior; STIs - Sexually Transmitted Infections; PWID - People Who Inject Drugs; FSW - Female Sex Workers; YRSB - Young Risky Sexual Behavior.

Source of funding: Financial support for this study was provided by a grant from the Shiraz University of Medical Sciences.

Conflicts of interest: The authors declare no conflicts of interest.

\section{References}

1. Derbie A, Assefa M, Mekonnen D, et al. Risky sexual behaviour and associated factors among students of Debre Tabor University, Northwest Ethiopia: a cross-sectional study. EJHD 2016; 30(1): 11-18.

2. Kassa M, Tesfaye E, Alamrew Z. Risky sexual behaviour among big construction enterprise workers; Bahir Dar City, Amhara Regional State, Northwest Ethiopia. IJCM 2013; 4(6): 296-303.

3. Mulu W, Yimer M, Abera B. Sexual behaviours and associated factors among students at Bahir Dar University: a cross sectional study. Reprod Health 2014; 11(1): 84.

4. Caico C. Sexually risky behavior in college-aged students. OJPM 2014; 4(5): 354-364.

5. Odinokova V, Dompalma-Linuza E, Karnite A, et al. Experimenting with drugs as predictor of unprotected sex among youth in Russia, Latvia and Poland: Maia Rusakova. Eur J Public Health 2015; 25(Suppl. 3), doi: 10.1093/eurpub/ckv175.146.

6. Golbasi Z, Kelleci M. Sexual experience and risky sexual behaviours of Turkish university students. Arch Gynecol Obstet 2011; 283(3): 531-537.

7. Debebe W, Solomon S. Sexual risk behaviors and its associated factors among undergraduate students in Madda Walabu University, Southeast Ethiopia: a facility based cross sectional study. Epidemiology: Open Access 2015; 5(4), doi: 10.4172/2161-1165.1000207.

8. Brian AJI, Umeononihu O, Echendu AD, et al. Sexual behaviour among students in a tertiary educational institution in Southeast Nigeria. A R Sci 2016; 4(3): 87-92.

9. Maheswari SU, Kalaivani S. Pattern of sexual behavior in adolescents and young adults attending STD clinic in a tertiary care center in South India. Indian J Sex Transm Dis AIDS 2017; 38(2): 171-175.

10. Zhang D, Pan H, Cui B, et al. Sexual behaviors and awareness of sexually transmitted infections among Chinese university students. J Infect Dev Countries 2013; 7(12): 966-974.

11. Ghaffari M, Gharghani ZG, Mehrabi Y, et al. Premarital sexual intercourse-related individual factors among Iranian adolescents: a qualitative study. Iran Red Crescent Med J 2016; 18(2): e21220.

12. Sharifi H, Mirzazadeh A, Shokoohi M, et al. Estimation of HIV incidence and its trend in three key populations in Iran. PloS ONE 2018; 13(11): e0207681.

13. Darban-Sarokhalil D. Infections in Iran. New Microbes New Infect 2019; 27: 7-8.

14. Safiri S, Rahimi-Movaghar A, Yunesian M, et al. Subgrouping of risky behaviors among Iranian college students: a latent class analysis. Neuropsychiatr Dis Treat 2016; 12: 1809-1816.

15. Mohammadpooras A, Ghahramanloo AA, Allahverdipour H. Risk-taking behaviors and subgrouping of college students: a latent class analysis. Am J Mens Health 2013; 7(6): 475-481.

16. Yi S, Poudel KC, Yasuoka J, et al. Role of risk and protective factors in risky sexual behavior among high school students in Cambodia. BMC Public Health 2010; 10(1): 477.

17. Sicard S, Mayet A, Duron S, et al. Factor associated with risky sexual behaviors among the French general population. J Public Health 2016; 39(3): 523-529.

18. Magnusson B, Crandall A, Evans K. Early sexual debut and risky sex in young adults: the role of low self-control. BMC Public Health 2019; 19(1): 1483, doi: 10.1186/s12889-019-7734-9.

19. Badillo-Viloria M, Sánchez XM, Vásquez MB, et al. Risky sexual behaviors and associated factors among university students in Barranquilla, Colombia 2019. Enfermeria Global 2020; 59: 436-449.

20. Sedighian $M$, Babazadeh T, Asghari Jafarabadi M, et al. Comparison of cognitive-emotional determinants of sexual high-risk behaviors amongst youth: an application of prototype willingness model. Koomesh 2017; 19(3): 533-542.

21. Ghaffari M, Gharghani ZG, Rakhshanderou S, et al. The relationship between religious beliefs and behaviors and the intention of premarital sexual abstinence among Iranian youths. Health 2015; 2(2): 15-21.

22. Afrashteh $\mathrm{S}$, Ghaem H, Abbasi-Ghahramanloo A. Clustering and combining pattern of high-risk behaviors among Iranian university students: a latent class analysis. J Res Health Sci 2017; 17(4): 398.

23. Dave VR, Makwana NR, Yadav BS, et al. A study on high-risk premarital sexual behavior of college going male students in Jamnagar City of Gujarat, India. Int J High Risk Behav Addict 2013; 2(3): 112-116.

24. Mulugeta $Y$, Berhane $Y$. Factors associated with pre-marital sexual debut among unmarried high school female students in bahir Dar town, Ethiopia: cross-sectional study. Reprod Health 2014; 11(1): 40, doi: 10.1186/1742-4755-11-40.

25. Dimbuene ZT, Defo BK. Family environment and premarital intercourse in Bandjoun (West Cameroon). Arch Sex Behav 2012; 41(2): 351-361.

26. Yip PS, Zhang H, Lam T-H, et al. Sex knowledge, attitudes, and high-risk sexual behaviors among unmarried youth in Hong Kong. BMC Public Health 2013; 13(1): 691.

27. Farahani FKA, Cleland J, Mehryar AH. Associations between family factors and premarital heterosexual relationships among female college students in Tehran. Int Perspect Sex Reprod Health 2011; 37(1): 30-39, doi: 10.1363/3703011.

28. Psutka R, Connor J, Cousins K, et al. Sexual health, risks, and experiences of New Zealand university students: findings from a national cross-sectional study. NZMJ 2012; 125(1361): 62-73.

29. Rahmati-Najarkolaei F, Kamalikhah T. The comparative health-risk behaviors between boys and girls of freshmen at University of Tehran, Iran. Iranian Journal of Health Sciences 2014; 2(3): 15-23.

30. Allahverdipour $\mathrm{H}$, Abbasi-Ghahramanloo A, Mohammadpoorasl A, et al. Cigarette smoking and its relationship with perceived familial support and religiosity of university students in Tabriz. Iran J Psychiatry 2015; 10(3): 136-143.

31. Sun X, Liu X, Shi Y, et al. Determinants of risky sexual behavior and condom use among college students in China. AIDS Care 2013; 25(6): $775-783$. 
32. Honarvar B, Salehi F, Barfi R, et al. Attitudes toward and experience of singles with premarital sex: a population-based study in Shiraz, southern Iran. Arch Sex Behav 2016; 45(2): 395-402.

33. Noroozi M, Taleghani F, Merghati-Khoei ES, et al. Premarital sexual relationships: explanation of the actions and functions of family. Iran J Nurs Midwifery Res 2014; 19(4): 424-431.

34. Abebe M, Tsion A, Netsanet F. Living with parents and risky sexual behaviors among preparatory school students in Jimma zone, South west Ethiopia. Afr Health Sci 2013; 13(2): 498-506.

35. Simons LG, Burt CH, Peterson FR. The effect of religion on risky sexual behavior among college students. Deviant Behav 2009; 30(5): 467-485.

36. Santelli JS, Song X, Holden IK, et al. Prevalence of sexual experience and initiation of sexual intercourse among adolescents, Rakai District, Uganda, 1994-2011. J Adolesc Health 2015; 57(5): 496-505.

37. Choudhry V, Agardh A, Stafström M, et al. Patterns of alcohol consumption and risky sexual behavior: a cross-sectional study among Ugandan university students. BMC Public Health 2014; 114(1), doi: 10.1186/1471-2458-14-128.

38. Abbasi-Ghahramanloo A, Rahimi-Movaghar A, Zeraati H. Fotouhi Pattern of substance use among students of medical sciences in Tehran, Iran: a latent class analysis. Journal of Substance Use 2018; 23(6): 648-654, doi: 10.1080/14659891.2018.1489007.

39. Woodford MR, Krentzman AR, Gattis MN. Alcohol and drug use among sexual minority college students and their heterosexual counterparts: the effects of experiencing and witnessing incivility and hostility on campus. Subst Abuse Rehabil 2012; 3: 11-23.

Tables: 3

Figures: 0

References: 39

Received: 26.06.2019

Reviewed: 26.01.2020

Accepted: 9.08.2020

Address for correspondence:

Haleh, Ghaem PhD

Research Center for Health Sciences

Institute of Health

Department of Epidemiology

School of Health

Shiraz University of Medical Sciences

Shiraz

Iran

Tel.: +98-71-37256007

E-mail: ghaemh@sums.ac.ir 